\title{
Managing Dramaturgical Dilemmas: Youth Drinking and Multiple Identities
}

Purpose This article seeks to understand how young people manage the dramaturgical dilemmas related to drinking alcohol and performing multiple identities.

Design/ methodology/ approach Drawing on qualitative data collected with 16-18 year olds, the authors adopt Goffman's dramaturgical perspective to examine youth alcohol consumption in relation to multiple identities.

Findings Young people continuously and skillfully juggle multiple identities across multiple contexts, where identities overflow, and audiences and interactions overlap. Techniques of audience segregation, mystification and misrepresentation, and justification are used to perform and manage multiple identities in a risky health behaviour context.

Research limitations/ implications The approach may facilitate some over- and underclaiming. Future studies could observe young people's performances of self across multiple contexts, paying particular attention to how alcohol features in these performances.

Social implications Social marketing campaigns should demonstrate an understanding of how alcohol relates to the contexts of youth lives beyond the 'night out', and engage more directly with young peoples' navigation between different identities, contexts and audiences. Campaigns could tap into the secretive nature of youth alcohol consumption and discourage youth from prioritising audience segregation and mystification above their own safety.

Originality/ value Extant work has argued that consumers find multiplicity unmanageable or manage multiple identities through internal dialogue. Instead, this paper demonstrates how young people manage multiple identities through interaction and performance. Our study challenges the neat compartmentalisation of identities identified in prior literature, and Goffman's clear-cut division of performances into front and back stage. 
Keywords: Alcohol, Goffman, Multiple Identities, Youth, Visual Methods, Interviews

\section{Introduction}

The role that alcohol and intoxication plays in young people's lives and identities has been well documented (Griffin et al., 2009; Piacentini et al., 2012). Recent research has focused on the social context of the 'night out', with the most excessive or extreme forms of drinking capturing the researcher imagination (Thurnell-Read, 2015; Maclean, 2016; Griffin et al., 2009). Additionally, the relatively recent polarization of drinking behaviours amongst young people (Measham, 2008) has led researchers to focus on either contexts of heavy or excessive drinking or those of abstention and light drinking (Martinic and Measham, 2008; Szmigin et al., 2008; Piacentini et al., 2012; Nairn et al., 2006). Little research, however, directly addresses the role that alcohol plays in the multiple contexts of people's lives (Thurnell-Read, 2015), and for young people in particular, there is limited understanding of the role of alcohol across a range of situations (such as home, school and athletic settings) as well as the social context. Exceptions include the influential work, Learning to Labour by Paul Willis (1977), which argues that young working-class 'lads' used alcohol to resist the culture of the school and to ready themselves for a life of labour. In addition, more recent work by Szmigin et al (2008, p 4), argued that youth intoxication and drunkenness can represent a "form of planned letting go", a way for young people to balance out, or respond to the more formal and structured aspects of their lives of work or school. Beyond these few studies that consider alcohol in relation to the wider settings of youth lives, extant research has yet to examine how young people navigate the multiple audiences and contexts of their lives, each with different alcohol-related norms, rules and expectations. This paper is focused on addressing this gap in understanding, drawing on the idea of dramaturgical dilemmas 
(from Goffman, 1961) to develop new understanding of the management and performance of multiple selves in context.

The tensions, dilemmas and conflicts of drinking alcohol have been identified as fruitful avenues for academic research (Thurnell-Read, 2015). Young people use alcohol to define or project the self (Haines et al., 2009; Rudolfsdottir and Morgan, 2009) yet alcohol also contributes to the "disturbance of identity" (Nairn et al., 2006, p. 297), making an individual act differently or "out-of-character" (Hartley et al., 2014, p. 782). Alcohol is viewed as a source of fun and enjoyment in some peer-based contexts (Coleman and Cater, 2005; Griffin et al., 2009), yet can be viewed as troublesome, immature or irresponsible behaviour by parents, teachers and other authority figures (Hackley et al., 2013). Different audiences and contexts place competing demands and expectations on young people with regards to alcohol. This conflicted culture informs varying views of who young people should or ought to be, as well as how they should or ought to consume alcohol, inevitably impacting upon the management and performance of their identities (Goffman, 1961). For youths, there are myriad interactions with different audiences, and these contexts bring different norms, rules and expectations around youth drinking. The stakes associated with breaking these norms, rules and expectations are high, and as such, young people's performances relating to alcohol consumption provide a particularly compelling vantage point from which to explore the management of multiple identities. In this paper, we understand youth and alcohol as a context laden with dramaturgical dilemmas of interaction (Scott, 2005), a term we use to capture the quandaries faced by individuals attempting to deal with potentially inconsistent identity performances as they interact with multiple audiences. The purpose of this study, therefore, is to explore how young people manage the tensions and dilemmas involved in drinking alcohol, and performing the self for multiple audiences with different norms, rules and expectations around alcohol and drunkenness. This paper demonstrates that youth 
drinking can be understood as a simultaneously front and back stage phenomenon, offering a more complex assessment of Goffman's (1959) front and back stage division, thereby advancing understanding of the motivations and dynamic interactions of young drinkers and their management of multiple identities.

Analysing qualitative data collected with 16-18 year olds using Goffman's work on impression management and dramaturgy, our findings show that young people employ techniques of audience segregation, mystification and misrepresentation, and justification to manage and perform multiple identities. These findings make several contributions to the literature. First, these findings contribute to the literature on youth alcohol consumption by offering an understanding of how young people manage the tensions and dilemmas involved in drinking alcohol. Second, our Goffmanian dramaturgical perspective offers an alternative theorisation that sheds new light on the management of multiple identities, as complex interactionist practices. In contrast to studies that have argued that consumers find multiplicity unmanageable (Carrington et al. 2015) or that they manage multiple identities through internal dialogue (Bahl and Milne, 2010), we show that young consumers experience multiplicity as manageable; our informants manage their identities through their interactions with various audiences, as they move through the multiple contexts or regions of their lives. Overall, our findings suggest that young people frequently switch between multiple front and back stage identities and performances, as they encounter different audiences and everchanging contexts. From a social marketing perspective, our paper contributes to a fuller picture of the consumer immersed within broader socio-cultural contexts (Brennan et al., 2014), which is important for developing campaigns aimed at supporting safe and sensible approaches to alcohol consumption (Szmigin et al., 2011).

Our paper begins with a review of the literature on multiple identities and risky health behaviours. We then introduce Goffman's dramaturgical perspective, before providing a 
description of our qualitative methodology. The findings are then presented, followed by a discussion of the contributions arising from our research. Finally, we examine the implications of our findings for the development of social marketing campaigns aimed at encouraging sensible and responsible drinking among youth.

\section{Multiple Identities and Risky Health Behaviours}

The social sciences have long recognised that individuals have multiple identities (e.g. James, 1890; Gergen, 1991; Goffman, 1961) and that the self we choose to present may differ depending on the audience and the social setting. For Goffman (1961) the individual can be considered as a "holding company" of multiple identities, focused on managing these multiple identities to retain some sense of stability, coherence and conflict avoidance. Goffman suggests that individuals engage in a form of audience segregation to manage multiple identities, referred to as the individual's efforts to ensure that "those before whom he plays one of his parts will not be the same individuals before whom he plays a different part in another setting" $(1959, \mathrm{p} .43)$. However, this vast array of potential identities available to individuals can play a role in creating dilemmas, tensions and conflicts (Bauman, 2001). Recent work has drawn on Goffman (1959) to show how young men adopt multiple identities and adjust their performance of self to suit the audience and the context, a process of "chameleonisation" and a "constant practice of code-shifting" (Ward, 2015, p.222). Ward (2015) notes how engaging in risky health behaviours such as drinking alcohol can help young men perform identities acceptable in some contexts (e.g. peer context) but hinder the successful performance of identities activated in other contexts (e.g. academic and athletic contexts).

While there is agreement over the notion that individuals have multiple identities, there is some disagreement over how consumers experience or deal with this multiplicity. 
Some scholars argue that consumers find multiplicity unmanageable (Carrington et al., 2015) and desire a coherent sense of self (Ahuvia, 2005), whereas others emphasize how consumers find enjoyment and value in having a multiple, fragmented self and find the ability to switch between different identities liberating (Firat et al., 1995; Goulding et al., 2002). Consumer research studies have examined the strategies used to avoid or manage conflicts and tensions between identities (Ahuvia, 2005; Tian and Belk, 2005; Bahl and Milne, 2010). These include the demarcating, compromising, and synthesizing solutions in Ahuvia (2005); the revealing and concealing strategies in Tian and Belk (2005); plus the various types of dialogical relationships which occur between multiple identities as discussed in Bahl and Milne (2010). These studies have shown that consumers make use of loved objects (Ahuvia, 2005), they extend and retract the self (Tian and Belk, 2005), or engage in internal dialogue (Bahl and Milne, 2010) to manage multiple identities. By focusing on youth alcohol consumption, a context laden with dramaturgical dilemmas of interaction, this study offers a more comprehensive understanding of how consumers manage multiple identities through their interactions with various audiences, as they move through the different contexts of their lives.

Extant research has examined multiple identities in relation to risky health behaviours, with most work focused on smoking. For instance, to navigate between multiple identities, a participant in Bahl and Milne's (2010) study compartmentalised smoking to her social self, smoking only when in the company of friends. Hamilton and Hassan (2010) draw on selfdiscrepancy theory (Higgins, 1987) to explore consumers' multi-dimensional self-concept in a smoking context, identifying discrepancies and conflicts between consumers' actual selves and ought selves, incorporating the demands, expectations, obligations and responsibilities placed on an identity by oneself or others. Elsewhere, Nachtigal and Kidron (2015) demonstrated that smokers experience a hybrid or composite self, and find they are often 
negotiating and oscillating between multiple identities of 'smoker' and 'non-smoker' during their attempts to quit smoking. Thompson et al., (2009) challenge the permanent identities of smoker/non-smoker, conceptualizing social smokers as occupying nomadic identities that are temporarily constructed and deconstructed as they move between different situations or contexts. Within the alcohol consumption context, recent research has shown how consumers have compartmentalisation tendencies, displaying multiple drinking identities (such as 'me drinking at social events', 'me drinking on holidays'), whereby drinking is justified by compartmentalising these various drinking identities (Gregory-Smith and Manika, 2017, p. 21). These studies together suggest that there is a strong performance aspect to these risky health behaviours, and that consumers are engaged in an on-going process of managing their interactions with different audiences by developing different personas. Understanding how these risky health behaviours are performed and managed in relation to multiple audiences and identities can be a fruitful avenue of inquiry. From this position, this paper takes a dramaturgical perspective to better understand the performance of multiple identities within the context of youth alcohol consumption.

\section{Goffman's Dramaturgical Perspective}

Goffman's (1959) dramaturgical perspective uses the theatrical metaphor to examine day-to-day performances and impression management, and this perspective has been emphasized in the marketing and consumer research literature (Fisk and Grove, 1996), with recent applications found in studies of fashion blogging (McQuarrie et al., 2013) and selfie postings (Pounders et al. 2016). Goffman assumes that individuals have the ability and motivation to control the impression they make on others across different social settings. Individuals are inclined to present idealized impressions to their audiences, modifying and adapting their performances to suit the understandings, expectations and values of society. 
Herein lies the notion of dramaturgical dilemmas. Drawing on Scott (2005), we use this term to encapsulate the difficulties individuals face dealing with, or reconciling, potentially inconsistent identity performances and multiple audiences. A key aspect of the required selfpresentation in the face of such dilemmas is the maintenance of 'front', that part of the individual's performance, which functions in a general and fixed fashion for the situation and observers of the performance (Goffman, 1959, p. 486). Actions that are incompatible with these idealized standards are often concealed in the maintenance of front, while other actions may be accentuated, and this process is labelled mystification. Mystification facilitates a degree of social distance between the performer and audience and allows the performer the space to craft the impression of their choice. Individuals may also modify their personal front in ways that would be considered misrepresentative - for example under-age drinkers who position themselves as over eighteen in order to be served alcohol (Goffman, 1959). For Goffman, techniques of misrepresentation can include strategic ambiguity, crucial omissions/non-disclosure, and prevention of discovery. Other techniques of misrepresentation have been identified in consumption research on fashion bloggers. Bloggers employ the techniques of feigning similarity and engaging in self-deprecation to maintain their audience and appear 'ordinary' and unchanged by their success, denying the boundaries that exist between themselves and their audience (McQuarrie et al., 2013).

Performances are often undertaken by teams and take place in 'regions' (Goffman 1959 , p. 2), those places that are "bounded to some degree by barriers to perception" such as the work region or recreation region. Regions typically consist of a front stage, where the performance takes place, and backstage, where the performance is often contradicted or where the front is dropped or relaxed. Whether a region should be defined as a front or back region depends on the perspective taken: "we speak from the reference point of a particular performance" (Goffman, 1959, p. 111). When speaking from the reference point of a 
particular performance, there will be regions that are neither front nor back stage and Goffman (1959, p. 115) refers to these as "outside". However, Goffman (1959) suggests that the "outside" should be used with caution, as shifting the focus away from the front and back regions to the "outside" can result in a tendency to move the point of reference to a different performance. Regions can be transformed into backstage regions by invoking backstage styles of language or behaviours such as "profanity", "open sexual remarks", "smoking", "shouting", "playful aggressivity and kidding” and "inconsiderateness for the other" (p. 111). Drawing on Goffman's theories of impression management, youth alcohol consumption is often understood as a form of backstage activity "secluded from the adult gaze", yet they are also "front-stage performances where young people stage an impression for the peer audience" (Johnson, 2013, p. 749). Despite acknowledging that youth drinking can be simultaneously a front and back-stage performance of self depending on the audience (Johnson, 2013), there has yet to be any further development of this idea in the literature, nor has there been any exploration of how young people negotiate drinking and drunkenness and the multiple front and back stages of their lives (in recreational, home, school and sporting contexts). This gap in our understanding forms the basis of our central research question: how do young people manage the tensions and dilemmas involved in drinking alcohol, and from this, how do they successfully perform the self for multiple audiences with different rules and expectations around alcohol? By addressing this gap, we are developing understanding of the nature of young people's performance of self, and how they switch between front and back stage to manage their identity for multiple audiences in risky consumption contexts. The next section of the paper describes the methodological approach adopted in this work to address these questions. 


\section{Method}

This study explored the alcohol consumption and multiple identities of young people, living in the North of England, aged 16-18 years. There were 91 participants (48 male, 43 female), from four different educational institutions, including two secondary schools (sixth formers), one Further Education and Training College (a college providing apprenticeships, entry to employment schemes etc.) and a Sixth Form College. This resulted in a diverse sample in terms of educational experience, localities and social class backgrounds. With the legal drinking age in the UK set at 18, 10 of the 91 participants were legally allowed to consume alcohol, and 81 were classified as underage drinkers. Ethical approval was sought and granted by the university's research ethics committee.

A multi-method, multi-stage approach was adopted to identify participants' multiple identities, and to explore alcohol consumption from the perspective of these identities. We employed 'methodological triangulation' (Denzin, 1978), adopting a range of different methods to ensure a 'fit' between method and informant, thus improving the richness and quality of data. There were four main stages to the research, and these complementary methods (Heath and Walker, 2012) were used to identify and bring to life participants' multiple identities. The stages of data collection are outlined in Table 1.

Table 1: Research methodology

\begin{tabular}{|l|l|l|l|}
\hline Name/ & Description & Purpose & $\begin{array}{l}\text { Academic } \\
\text { underpinning }\end{array}$ \\
\hline $\begin{array}{l}\text { 1. Written } \\
\text { answer } \\
\text { booklets }\end{array}$ & $\begin{array}{l}\text { Series of open-ended } \\
\text { questions on } \\
\text { participants' } \\
\text { attachments to }\end{array}$ & $\begin{array}{l}\text { To uncover } \\
\text { participants' } \\
\text { multiple identities } \\
\text { associated with, and }\end{array}$ & $\begin{array}{l}\text { Adapted from Bahl } \\
\text { and Milne (2010) } \\
\text { who used a similar } \\
\text { approach to study }\end{array}$ \\
\hline
\end{tabular}




\begin{tabular}{|c|c|c|c|}
\hline & $\begin{array}{l}\text { people, places, } \\
\text { possessions, key } \\
\text { events and } \\
\text { experiences. }\end{array}$ & $\begin{array}{l}\text { underpinned by, } \\
\text { varying sets of } \\
\text { attachments. }\end{array}$ & $\begin{array}{l}\text { multiple identities } \\
\text { and consumption } \\
\text { experiences. }\end{array}$ \\
\hline $\begin{array}{l}2 . \\
\text { Clustering } \\
\text { Task }\end{array}$ & $\begin{array}{l}\text { Participants } \\
\text { combined written } \\
\text { answers with photos } \\
\text { or images that "tell } \\
\text { who you are" or } \\
\text { "reflect things of } \\
\text { importance in your } \\
\text { everyday life" }\end{array}$ & $\begin{array}{l}\text { To produce clusters } \\
\text { that represent } \\
\text { different aspects of } \\
\text { who they are, } \\
\text { providing visual } \\
\text { representation of } \\
\text { multiple identities. }\end{array}$ & $\begin{array}{l}\text { The questions used } \\
\text { mimic those } \\
\text { developed by } \\
\text { Kjeldgaard and } \\
\text { Askegaard (2006, p. } \\
\text { 235) in their } \\
\text { "photographic life } \\
\text { description" task. }\end{array}$ \\
\hline $\begin{array}{l}\text { 3. Avatar } \\
\text { creation }\end{array}$ & $\begin{array}{l}\text { Participants created } \\
\text { a set of unique } \\
\text { finely-tuned 3D } \\
\text { avatars (using Sims } \\
3 \text { software) }\end{array}$ & $\begin{array}{l}\text { To animate and } \\
\text { bring to life identity } \\
\text { projections, as a } \\
\text { basis for deeper } \\
\text { reflection on their } \\
\text { multiple identities } \\
\text { identified in the } \\
\text { cluster task. }\end{array}$ & $\begin{array}{l}\text { Adapted from } \\
\text { Kozinets and } \\
\text { Kedzior's (2009,p. } \\
\text { 4) "animated } \\
\text { representations". } \\
\text { Responds to Gould's } \\
\text { (2010) suggestion } \\
\text { that researchers "ask } \\
\text { consumers to draw } \\
\text { their own pictures, } \\
\text { figures or models of } \\
\text { their self/selves" } \\
\text { (P.207) }\end{array}$ \\
\hline $\begin{array}{l}\text { 4. Paired } \\
\text { and group } \\
\text { interviews }\end{array}$ & $\begin{array}{l}17 \text { interviews in } \\
\text { total, featured 2-8 } \\
\text { participants, both } \\
\text { same-sex and mix- } \\
\text { sex groupings based } \\
\text { on friendship groups, } \\
\text { 40-60 minutes long } \\
\text { within a } \\
\text { common/break out } \\
\text { space, recorded and } \\
\text { transcribed verbatim. }\end{array}$ & $\begin{array}{l}\text { To further explore } \\
\text { participants' alcohol } \\
\text { consumption in } \\
\text { relation to their } \\
\text { multiple identities } \\
\text { and the multiple } \\
\text { contexts of their } \\
\text { lives (including } \\
\text { family, friends/peers, } \\
\text { education and } \\
\text { sports). }\end{array}$ & $\begin{array}{l}\text { Semi-structured } \\
\text { approach based on } \\
\text { McCracken's (1988) } \\
\text { approach. Interview } \\
\text { guide featured grand } \\
\text { tour questions and } \\
\text { more specific } \\
\text { probes. }\end{array}$ \\
\hline
\end{tabular}

Recent work in sociology has discussed the complementary nature of interviewing methods and Goffman's dramaturgical framework, in terms of their ability to elicit front stage and 
back stage 'talk' (Robinson and Schulz, 2016), and several studies have applied Goffman's work on dramaturgy and impression management to the analysis of group interviews on teenage drinking (Demant and Järvinen, 2006; Johnson, 2013). Group interviews are particularly suitable for the application of Goffman's work on dramaturgy and impression management as youth drinking predominantly takes place in a peer context, and drinking plays an important role in the formation of peer identities. Group interviews allow for an understanding of young people's behaviour and experiences around alcohol and "how these are constructed and articulated in the context of a peer culture" (Johnson, 2013, p.750). Furthermore, it has been proposed that a Goffmanian dramaturgical perspective can be incorporated into the interview method by activating multiple identities and asking front stage questions that feature institutional representatives and back stage questions that feature someone the participant could talk freely to about the context (Robinson and Schulz, 2016). While we did not follow this approach precisely, our approach did incorporate the activation of multiple identities prior to, and during the interview, using various techniques (see Table 1) and the inclusion of both back stage and front stage questions. Although group interviews do not allow the observation of drinking behaviours and interactions across multiple contexts, they do provide valuable insight into young people's experiences and encounters outside of the interview context, and are often a reflection of behaviour outside this context (Johnson, 2013). Of course, the role of the researcher and other group members can influence the responses provided by the individual and they may be inclined to misrepresent their alcohol consumption. However, prior work on youth alcohol consumption has revealed a "moral requirement for individuals to be what they claim" with a tendency for peers to criticize their friends for "over-claiming" or "acting hard", if they are seen to be exaggerating their alcohol consumption (Johnson, 2012). Crucially, this research was less interested in the frequency of drinking and the quantities consumed, rather we were interested in the techniques young 
people use to manage the tensions and dilemmas involved in drinking alcohol and successfully perform the self for multiple audiences.

Data analysis and interpretation began during data collection and continued after all the data had been collected and transcribed. Pseudonyms were used to ensure participant anonymity. To organize the visual and text-based data, we used NVivo qualitative data analysis software programme. While NVivo aided the analysis and interpretation of data through a process of note taking, memo-writing and provisional labelling of data, the bulk of the coding and categorization of data was carried out manually. An initial round of data analysis involved identifying provisional categories or themes in each form of data, and moving back-and-forth between individual cases/data types and the entire data set, to generate a holistic understanding and unified interpretation of the data. Analysis involved a process of categorization, abstraction, comparison and integration (Spiggle, 1994). A second round of analysis involved applying some of the detailed coding procedures provided by Charmaz (2006) and Saldana (2009), employing open and axial coding techniques. Coding was driven inductively by searching for emergent themes and deductively informed by theoretical concepts identified in the literature. Goffman's dramaturgy and impression management emerged as a useful theoretical framework, and our analysis operates on two levels using this frame. First, we analyse participants' accounts of their encounters and performances of self as they navigate the multiple contexts of their lives and interact with various audiences, in relation to alcohol consumption. Second, we observe the interactions that take place in the group interview context where young people are articulating their experiences of navigating the multiple audiences and contexts of their lives for both a peer and adult audience. We recognize that the group interview presents a situation where participants are inevitably staging the self for the peer audience (their friends also participating in the focus group) but 
also for an adult audience (the researcher), and we take this into consideration throughout our analysis. The findings show how young people manage multiple identities in a consumption context laden with dramaturgical dilemmas, revealing three different techniques used to manage these dilemmas, when navigating different audiences and social settings in an alcohol context.

\section{Findings}

Techniques of Audience Segregation: Compartmentalising drinking and drunkenness Performing the self for multiple audiences with different expectations around drinking and drunkenness can inevitably create dramaturgical dilemmas for young people. The first technique employed by youth to deal with potential dramaturgical dilemmas is to segregate audiences and compartmentalise drinking and drunkenness to specific regions. Participants consistently incorporated images of alcohol to represent their 'social self' or their 'party self' (the party self associated with highest levels of alcohol consumption), illustrating the clusters of Hermione, Scarlett and Oliver. Hermione (age 17) included a hand-drawn image of a bottle of vodka in the cluster representing her 'social' self and Scarlett (age 17) included 'drinking' in the cluster representing her 'socialising' self, distinct from her 'career' self focused on identity performances of doing schoolwork, achieving good grades and getting into university (Figure 1). Oliver (age 17) included an image of a row of spirits bottles behind a bar in the cluster representing his 'partying and friends' self. For each of these participants, the consumption of alcohol is clearly compartmentalised to varying performances of their social selves. 
This compartmentalisation represents a form of "audience segregation" (Goffman 1959, p. 43). These performances of self are often influenced by the demands and expectations of the region and its audience (Goffman 1961). Oliver and Jason discussed drinking to intoxication with their friendship groups at the weekend, explaining that their behaviour is compartmentalised to social identities performed only at the weekends, thereby allowing them to successfully perform their academic identities in the weekday front stage of the school.

Jason: We discovered in Mr Green's lesson that we are the alcoholics of the psychology class.

Oliver: Yeah...In the space of a weekend, in the two days, we drink the whole weekly allowance of a man.

Jason: That's on average though...not every weekend.

Oliver: Not every weekend but I'm close...I don't tend to drink during the week, I go out and see friends...I go round to his [points to Jason] house now and again. Drinking is usually saved for the weekends.

Jason: We still concentrate on our work though...we do very well, and we're good at splitting the two off.

Jason and Oliver dramatize the excessive nature of their alcohol consumption using the label "alcoholic" and the use of units or "weekly allowance of a man", demonstrating the important role alcohol plays in the performance of peer identities (status and ability to drink like a 'man'), while also conveying the compartmentalised nature of this excessive alcohol consumption. However, reassuring the researcher that excessive consumption does not occur 
every weekend and that they still concentrate on front stage activities such as schoolwork (through compartmentalisation), Jason engages in what Goffman (1959, p.167) terms "realigning actions". This realignment speaks to the conflicting and contradictory values that exist around alcohol in the UK (Hackley et al., 2013) and Jason is perhaps also seeking alignment with the researcher's assumed attitudes towards alcohol and convincing himself and the audience (other group interview participants and the researcher) that he can perform adequately for both the peer and adult audience.

Despite Oliver and Jason emphasizing their ability to successfully perform their multiple identities, the success of this strict segregation and compartmentalisation is challenged with their admission that a fuller picture of their alcohol consumption vis-à-vis their classmates emerged in the back stage (peer-to-peer) regions of the school. This discovery infers a degree of crossover between their weekend performance of alcohol-related identities and their weekday identities performed at school. In Goulding et al. 's, (2002) study, adult ravers were found to compartmentalise their alcohol and drug consumption to 'rave weekends', relying on there being little audience interaction and overlap for the expression of a responsible worker identity during the working week. In contrast, our Goffmanian lens demonstrates challenges to being able to completely compartmentalise alcohol consumption to specific identities, due to the degree of overlap between audiences. The same peer audience (friendship group) is often present in both drinking and educational contexts, leading to overlapping performances in these regions, with multiple front and back stage identities inescapably colliding, and thus requiring careful navigation. From a Goffmanian (1959) point of view and speaking from the reference point of performing academic identities within the front region of the school, alcohol-related discussions with friends at break-times can be understood as back stage behaviour. However, our findings support and develop Johnson's (2013) suggestion that youth alcohol consumption can be simultaneously a front and back 
stage performance. Beyond the actual consumption of alcohol, our findings show that alcohol-related discussions are not only back stage performances hidden from an audience of teachers, but also front stage performances for a peer group audience. Nevertheless, these drinking stories are typically compartmentalised to the backstage regions of school, segregating the peer audience from the teacher audience to manage different identities performed at school.

Our participants also engaged in audience segregation by displaying signs of drunkenness and intoxication with friends in contexts such as the house party or the pub, but ensuring that very few signs of their drinking were carried over into the front stage regions of the family home. This involves appreciating the "expressive requirements" of the audience and the situation (Goffman, 1959, p.48) and exercising expressive care when switching between identities and performances by ensuring that they "don't come home and be sick everywhere" (Jessica, age 16), do not act "stupid" (Louisa, age 16), or "too drunk" (George, age 17) and "don't wake my Dad up" (Eric, age 17). Navigation between these regions involved negotiating a safe and convincing return from the recreation region to the domestic region. Rather than navigating from a back stage to a front stage or vice versa, as was the focus of Goffman's (1959) research, here young people are moving across regions - from one front/back stage performance (socialising and partying with friends) to another (the "outside" region of the family home becomes front/back stage as young people enter the family home). However, given the nature of drunkenness and intoxication, it was not always possible for young people to compartmentalise alcohol to selves enacted outside of the domestic region. Events such as house parties or school/college-organised parties also prevented the neat and clear segregation of audiences with both peers and parents/teachers present in the same context. These situations can have a tendency to produce dramaturgical dilemmas in the form of role conflict or role strain, which Goffman explains is when an individual is forced to 
perform two identities simultaneously that do not fit well together. While this is usually avoided by the juggling of multiple identities in such a way that performances are kept separate - e.g. by using role segregation (performing one identity in a specific interaction context) or audience segregation (keeping separate audiences apart), in some instances this cannot be fully acted upon. Laney (age 17) notes the embarrassment she feels when unable to mobilize the technique of audience segregation: "If you go to a house party and their parents are in and you know them, that sort of stops you from drinking a bit don't it...that's embarrassing." Our findings suggest that the neat compartmentalisation of identities reported in previous work on risky consumption behaviours (Goulding et al. 2002; Gregory-Smith and Manika, 2017) is not always realistic or achievable.

Given the somewhat contradictory relationship between amateur/college sports and alcohol (Palmer, 2015), it was not surprising to find many instances of compartmentalisation and audience segregation around alcohol identities within the sports context. Some participants were able to neatly compartmentalise their alcohol consumption to the performance of identities outside of the sports context. Louisa included partying in the cluster representing her 'friendship' self but not in the cluster representing her 'sporty' self (see Figure 2) and confirmed that alcohol was compartmentalised to weekend identity performances ("I drink mainly at weekends at parties"); and therefore did not interfere with front stage performances of her 'sporty' self which occurred during the week ("I mainly play netball during the week").

\section{FIGURE 2 HERE}

However, it became evident in the clustering task that for other participants (typically male rugby players) alcohol played a more complicated role in identity performances and this was 
elaborated upon in the group discussion. Participants who played rugby tended to perform in accordance with the tacitly agreed norms and rules for alcohol consumption, structured around rugby matches and training - typically characterized by pre-match abstention followed by excessive post-rugby drinking. Post-rugby drinking with teammates/ friends is simultaneously a front and back stage performance (Johnson, 2013). It is back stage behaviour when considered from the perspective of the performance of a rugby identity, but is also a front stage performance when considered from the perspective of the performance of a social/ peer identity. By compartmentalising alcohol consumption in this way (pre-match abstention; post-match excessive drinking) these young male participants are able to maintain a successful front stage performance of their sporting identity (e.g. well-rested, physically prepared, dedicated to the sport). Philip (age 17) explained that the coach had told the team that they were not allowed to go out the night before a Sunday rugby match and that "Friday is the night you go out and Saturday night is when you're meant to get your sleep, get your rest". Philip demonstrates an appreciation for the protracted influence of alcohol, and how the performance of an alcohol-related identity can potentially hinder the successful front stage performance of their rugby identity. Participants from a different school, who played for the same local rugby club, echoed these comments:

Spencer: Do you remember your birthday being on the Saturday and us having a big game on the Sunday?

Harry: Yeah and we lost.

Jacob: Half the [rugby club] had been drinking the night before; we didn't stand a chance of winning.

Hugo: We've learnt from that though, before the game we won't drink but after the game we might...Yeah we can't drink the night before a game, we're not allowed, if we do it's for a birthday and it's a one off. 
Harry: Yeah it's only seasonal so it's not forever, so you just make the decision not to drink. Plus, we're defending champion so if we want a shot at winning we've got to make it a priority over the drinking.

Jacob: I'd say most of the people in our circle of friends play sport so they all understand anyway.

The group engage in retrospective staging talk, where performers reflect on their performance, what went wrong and how they can move on (Goffman, 1959). The discussion itself can also be read as an instance of staging talk, with the group making sense of their previous performance during this particular interaction. The above discussion demonstrates that young people are not always able to fully and neatly compartmentalise alcohol and its effects to specific audiences and regions. Despite limiting their drinking and drunkenness to a peer audience of teammates and friends in the context of the 'night out', the negative impact on front stage performances (playing rugby) is experienced, essentially front and backstage performances collide, preventing compartmentalisation. This protracted influence was also noted by a female hockey player, Millie (age 17): “I know if I've been to a party then have to get up for a hockey match the next day my legs just absolutely kill. I don't get hangovers but my legs kill and I just can't run and running is a key part of playing hockey." Millie is acknowledging the potential influence that alcohol consumption can have on performances of self ('hockey player' self) in regions “outside” (Goffman, 1959) of the recreation/ partying region (e.g. the sporting context). The sporting region is a place for performance of a different self (the hockey self), in front of a different audience (teammates, coaches, spectators), with its own front stage performance pressures, quite distinct from those related to the performance of the social self. This distinct front stage sporting performance, however, carries the impact of the effects and hangover from the social self (now considered 'outside' as Millie is not performing to a social audience), demonstrating how the various performance 
stages collide and form a dramaturgical dilemma and tension for the individual. This type of dramaturgical dilemma was most frequently expressed by participants in terms of dealing with a hangover the following day at school, or parents seeing them drunk when they return home from a 'night out'. This finding again challenges previous work in consumer research, which has discussed the fairly neat fragmentation of identities and compartmentalization of consumption practices in avoiding and managing conflicts and tensions between multiple identities (Goulding et al., 2002; Bahl and Milne, 2010). While our data shows that young people do seek to employ audience segregation and compartmentalize their alcohol, drinking and drunkenness, it also suggests a more complex and fluid understanding of multiple identities where aspects of one identity overlap and overflow into the contexts or regions where another identity is typically performed.

\section{Techniques of Mystification and Misrepresentation: Concealing and accentuating}

In their efforts to manage the dramaturgical dilemma of performing the self for multiple audiences with different expectations around alcohol, our participants engage in techniques of mystification and misrepresentation (Goffman, 1959) depending on the audience. Techniques of mystification are used to present idealized impressions to various audiences, which often meant concealing their drinking and drunkenness from parents, teachers and sports coaches, and accentuating their drinking and drunkenness when presenting to an audience of peers (school friends and teammates).

Our findings support previous work that has suggested that young people tend to "hide the extent of their drinking from outsiders including adults and other young people who might judge them" (Sheehan and Ridge, 2001, p.359). Concealing strategies were most prevalent amongst the younger participants (those aged 16) and/or those who received stricter parental rules in relation to alcohol. Various approaches were used to conceal or mask their 
alcohol consumption from responsible adults in contexts such as the home. While some conceal their drinking from both parents (for example Katy (age 16) “My parents don't know I drink"), we noted others adopting distinct approaches, depending on the family member. Sixteen-year-old Ellie states, "My Dad doesn't mind, My Mum doesn't know", while others co-opt family members (e.g. siblings) and friends to specifically conceal consumption from their parents. Jake (age 17) describes colluding with his aunt:

“I always say I'm stopping out somewhere when I'm going out drinking so my Mum doesn't think owt of it. Generally I'd get my auntie to say I was stopping there when I wasn't. I was staying out all night...that way I'd get away with it and there were no consequences or owt, which was all right."

Jake's admission implies engagement of both himself and his aunt in 'staging talk' (Goffman, 1959), where he and his aunt plan the performance (e.g. scripts, lines and moves) in relation to a specified audience (his mother). Canniford and Shankar (2013) identify "masking practices" of surfers concealing certain betrayals to maintain "nature and culture as separate zones" (p.1065), and these young consumers use similar techniques to mask or hide certain elements of their social life. Through mystification. excessive alcohol consumption is concealed from their parents and they maintain the distinction between two separate regions of their lives (social versus home performances). However, not all participants chose to conceal their drinking from their parents. Points of similarity are evident with Tian and Belk's (2005) study of multiple identities, which discussed consumer decisions to extend/reveal and retract/conceal aspects of self in different contexts. Take for instance, Chloe who initially identifies distinct 'family' and 'social' selves (see Figure 3). 


\section{FIGURE 3 HERE}

However, Chloe later reveals that rather than concealing her social self, she extends or reveals aspects (including alcohol consumption) when in the company of her parents. Her willingness to do so reveals her status as a drinker, yet her parents' willingness for this to happen minimises the potential for conflict ("My Mum and Dad don't mind it [drinking] because I'll happily do it in front of them and they've seen me drunk many times"). Or Henry who revealed aspects of his 'partying' self within the domestic field by displaying his collection of empty bottles (e.g. whisky bottles, beer bottles, spirit bottles) on the shelves in his bedroom. Although these were displayed within his backstage space (i.e. his bedroom) in the domestic field, he made no attempt to ensure his mother would not see these empty bottles. Additionally, some participants' parents appeared to deliberately attempt to demystify the consumption of alcohol through the purchase of small quantities of alcohol to be consumed as a family in the home, providing guidance around what they see as appropriate drinking behaviours.

Accentuating drinking and drunkenness has been described as a way for young people to take advantage of the cultural and symbolic capital associated with alcohol (Haines et al., 2011) and to gain status among their peer group (Demant and Jarvinen, 2006). Although we did see evidence of accentuation in our data, it was other members of the peer audience (not the individual themself) who made such instances visible to the researcher (through group discussion). Prior work on youth alcohol consumption has shown how over-claiming, exaggerating and embellishing drinking episodes as techniques of misrepresentation are often 
read by peers as "showing off" and cast as inauthentic performances (Johnson, 2013). In the following excerpt, Eric placed emphasis on getting drunk when not in school:

Eric: I socialize with anyone me. I like to get messy when I'm not in school. Others: (Laughter)

Researcher: What does get messy mean?

Eric: Erm I swear to God I've never said get messy before, don't know why I just said that. It just means we meet up and go out and get drunk. Why am I the only one talking? I went bowling with mates the other day.

Zain: He went bowling and got messy (laughs)

Eric's emphasis on getting drunk and use of the term "get messy" draws laughter rather than sympathetic tact (Goffman, 1959) from the group, and is then positioned by Eric himself as a faux pas and a one-off utterance. Given the above interaction took place at the start of the group discussion it could reveal Eric's initial uncertainty in performing the self and meeting the demands and expectations of both the peer and adult audiences (in this case the researcher) around alcohol.

Returning to the relationship between amateur sports and alcohol, we found evidence of techniques of mystification, and the concealing and accentuating of drinking and drunkenness, among our male rugby players. Phillip (age 17) offers one such example of these techniques of mystification:

Researcher: Do you drink with the lads at the [rugby club]?

Phillip: Yeah we have quite a few drinks after a game. You've got to drink it's like a rugby religion, go and have a pint after the game.

Researcher: And is it OK to just have one pint then leave?

Phillip: Not really, it's just whatever happens really. It's code-named... Researcher: What's code-named? 
Phillip: Can't say, it's like confidential. Rugby player's diaries.

Phillip is keen to conceal the details and extent of his alcohol consumption practices; as a front stage performance for peers, and a backstage activity secluded from the 'responsible' adult gaze. Phillip's efforts to conceal the details of the team's alcohol consumption could be understood in Goffman terms as keeping the team's “entrusted secrets” (Goffman, 1959). Phillip conceals aspects of his alcohol consumption practices by playing them down and being vague, but at the same time he accentuates other aspects such as talking about their performance front stage, i.e. on the rugby field: "we all just go and have a drink and talk about the game... about how we could improve and stuff." Phillip describes an approach to drinking at odds with the stereotypical image of how rugby club members engage in excessive drinking (Schacht, 1996). Phillip appears to be engaging in techniques of mystification by selectively choosing which aspects of his alcohol consumption practices to conceal and/or accentuate, to keep the audience at a distance and manage impressions of his rugby identity to those audiences outside the rugby setting. Phillip is also using many of the techniques of misrepresentation outlined by Goffman (1959) such as being ambiguous or vague, and omitting or choosing not to disclose certain information.

Techniques of misrepresentation were most prevalent in our data among the underage drinkers (16-17 year olds). Those under the legal drinking age made attempts to look over 18 to gain access to alcohol - either entry to bars and clubs, or being served alcohol. We term this specific technique 'feigning adulthood'. Young people modify their personal front to feign adulthood in ways that are misrepresentative (Goffman, 1959). For example, Phillip described attending bars and clubs with older members of the rugby team ("if you go out with the right people then it's fine") and growing his facial hair to appear older ("I look older...in a few days this [facial hair] will be out here"), and Jenson and Chloe discussed wearing $18^{\text {th }}$ 
birthday badges, using fake ID and socializing with a group of older friends to trick the door/bar staff into think they were eighteen:

Jenson: I've been given cheaper drinks just for wearing an 18 badge and letting everyone think it's my $18^{\text {th }}$

Chloe: Coz they think it's your birthday. We did that when we went out round Leeds Jenson: If you know any 17 year olds just tell them to wear an 18 badge if they don't want to get ID'ed.

Chloe: That's the thing, on my fake ID I'm 20 on it but I get away with it. Most of my friends are turning 20, 21 now so it's easier.

Jenson: It gets you in and then you get cheaper drinks. There's no other way unless you know the bouncers.

Techniques such as those employed by Phillip, Chloe and Jenson allow young people to navigate an adult audience of door/bar staff, and successfully perform the drinking self in the front stages of the bar/club for a peer audience.

\section{Techniques of Justification: Comparing, and postponing}

Various justifications are used by participants to deal with the dramaturgical dilemma of performing the self for multiple audiences with different expectations around alcohol. These justifications are use to neutralise or rationalize negative behaviours and can include denial of responsibility, denial of injury, condemning the condemners and appealing to higher loyalties (Sykes and Matza, 1957), and justifications by comparison, and postponement (Cromwell and Thurman, 2003). While we found evidence for each of the neutralisation techniques as identified by Piacentini et al., (2012) in their study of heavy drinkers and abstainers/nearabstainers, we focus here on the most prevalent and noteworthy neutralisation techniques 
used in this context, namely 'justifications by comparison' and 'justifications by postponement'.

For justifications by comparison, we found this approach mainly used when participants draw comparisons between their own alcohol consumption and those of other youth groups. While these comparisons reflect rhetorical techniques, they are also practical strategies of impression management, as individuals seek to perform to their peer group (other research participants) and the adult audience (researcher) and as such represent tools to deal with dramaturgical dilemmas. Many participants use the derogatory term 'chav' to present themselves as responsible and sensible drinkers in comparison to this other group (e.g. Lily's comment that "we can drink in moderation, chavs just hammer it"). The justifications by comparison evident in our data resemble Goffman's (1959) discussion of performers' treatment of an absent audience (p.149). Treatment of an absent audience can include ridiculing, gossiping about, criticizing or caricaturing an audience, serving to strengthen the cohesion and unity of the team (in this case the group interview participants). As Goffman (1959) states, "the audience may be referred to in their absence by a collective term combining distance and derogation, suggesting an in-group - out-group split” (p.152). Such techniques were drawn upon not only when relaxing and reflecting backstage in the company of teammates, but also when performing front stage for other audiences (in this case the adult researcher). These techniques are used to strengthen the solidarity of the group, but are also used to distance themselves from the negative perceptions of teenage drinkers and present themselves as being able to successfully perform an alcohol-related identity to an adult audience. Jenson and Chloe (both age 17) sought to forge a more favourable impression of their drinking behaviour, by making comparisons with the excessive drinking of other youth 
groups who they refer to as "crazier" and "twice as bad" (e.g. privileged youth and university students):

Jenson: It's like Grammar...people say 'oh they go to Grammar, they won't drink that much' but the Grammar people tend to be a lot crazier.

Chloe: Rydell school near us, it's a private school and they play a lot of sport but they drink more and they do a lot of drugs, they're twice as bad as what we are like at college.

Researcher: What are your expectations surrounding drinking at Uni?

Jenson: ...it's like festival drinking isn't it? If you go out on a bender you start drinking in the morning and you don't stop until you pass out.

Participants anticipated that their drinking would become more excessive and extreme when at university and employed 'justifications by postponement'. Jenson's use of "isn't it?" should be read in light of the interaction taking place with an adult researcher who has experienced university first-hand, and is perhaps a prompt for the researcher to continue this particular line. The use of "isn't it" implies a degree of mystification around alcohol and university. Rochelle (age 18) who currently drinks alcohol once a week, also expected her drinking to increase when she starts university next year: "I'll drink a lot more coz all my friends that have gone to Uni drink near enough every night...” In Piacentini et al.'s (2012) study, the young adult consumers justified their drinking by emphasizing the temporary nature of their drinking, a form of bounded excessive alcohol consumption associated with this period in their lives university students. Our younger informants called upon their expectations of how alcohol might feature in their future identities of 'university student' to justify, and manage impressions of their current drinking behaviour. This supports existing work that has looked at how future perceptions of self can influence current health-related 
behaviours (Lawton 2002). Oliver (age 16) justifies his current drinking behaviour as 'preparation' for when he takes on the role of 'university student' - an identity frequently linked to heavy drinking (Piacentini and Banister, 2009):

"I think now is more preparation for drinking at Uni. Uni is easier than sixth form apparently. You've got less subjects and it is one big party and you don't have to deal with teachers."

Oliver's comment highlights young people's perceptions of university as representing a region where partying ("one big party") is the main focus, operating as the front stage activity, taking precedence over university work (“less subjects”). The front and back stages of the academic environment become blurred for many young people. While we would expect performance of the academic student identity to have a central front stage performance played out in the front stage of the classroom, for many participants, their social identity dominates, leading to a complex interweaving of front and back stage performances around alcohol consumption. Given the importance of social and peer performance in young people's lives, socialising around alcohol can occupy both the front and back stage, even simultaneously. For example during classes alcohol may assume a front stage role when considered from the perspective of the 'social/ partying' self (e.g. chatting with friends). Oliver's comments that "you don't have to deal with teachers" also signals the perception of a more distant and less intimate or intensive performance at university, with less interaction between performers and the audience of teaching staff, thus making it appear easier for youth to navigate the multiple front/ back stages of socialising with friends and doing university work. The use of "I think" and "apparently" also signals that Oliver, a sixth form student, is not entirely sure what university life is like or how alcohol will fit into this. This suggests a degree of mystification around drinking at university, and given this interaction takes place 
with a researcher with first-hand experience of university life, Oliver delivers the "line" (Goffman, 1959) that university is 'one big party', with a degree of caution, rather than complete certainty. By holding back slightly, Oliver is acknowledging his lack of direct experience with university, and protecting himself from embarrassment, should this line be challenged by the researcher.

In contrast, those intending to move straight from school or college into paid employment used the 'justifications by postponement' technique differently. These participants justified their current alcohol consumption as making the most of having relatively few responsibilities before they enter full-time employment. They typically expected their alcohol consumption to decrease and/or become much more 'structured' (Harnett et al., 2010) around the working week, clearly occupying a backstage performance against the priority they give to the front stage performance of their career identity. Rather than choosing to attend university, Laney (age 17), a keen athlete, has decided to join the British Army. Laney speculates that drinking alcohol will not be compatible with the Army and so she intends to make the most of her summer period:

“Drinking definitely doesn't fit with sport or my future in the Army. Drinking is bad for your body, which my sport and future career in the Army rely on. Drinking just makes sport a lot harder to do and I definitely won't be able to drink in the Army. I think my drinking will like level off but I want my summer first. I think my drinking might stop because of the Army. I want my summer to have fun and drink lots, and then I'll join the Army and it'll change. I'm going to make the most of my summer.'

Laney is activating the 'justification by postponement' neutralisation technique to justify her current drinking behaviour and decision to "drink lots" over the summer - the liminal period betwixt and between (Turner, 1969) finishing school and starting full-time employment. 
Laney is also aware of the negative impact that alcohol can have on the body and how this could potentially hinder the successful performance of a future identity when she transitions from one region (high school) to another (work in the Army).

\section{Discussion}

Our study focused on the dramaturgical dilemmas young people faced around alcohol, and examined the techniques young people use to successfully perform and stage-manage multiple identities when navigating different audiences with competing demands and expectations (Thurnell-Read, 2015; Piacentini et al., 2012; Hackley et al., 2013). Extant research has argued that consumers find multiplicity unmanageable (Carrington et al. 2015) and cope with multiple identities through the use of internal dialogue (Bahl and Milne, 2010). In contrast, our interpretation develops understanding of the practical techniques that young people use for the "successful staging" of identities (Goffman, 1959) and management of the impressions they present to different audiences. We demonstrate that young consumers experience multiplicity as a manageable, and perhaps inevitable, aspect of this life stage of developing maturity. Our Goffmanian theorisation problematizes the fairly neat compartmentalisation and fragmentation of identities associated with risky consumption behaviours that has been suggested in other research (Goulding, 2002; Bahl and Milne, 2010). We provide an enriched understanding of how consumers manage multiple, conflicting identities that arise as a result of engaging in risky health behaviours, which could have connotations beyond the alcohol context, such as smoking (Bahl and Milne, 2010; Hamilton and Hassan, 2010) or drug consumption/rave culture (Goulding, 2002). This focus on identity performance allows us to consider alcohol's protracted influence. Alcohol is not experienced within just one social/ recreation region, and can compromise or impact upon the performance of identities even when the sports field, the home and the school take front 
stage. We therefore demonstrate how young consumers continuously and skilfully juggle multiple identities across multiple contexts, where identities overflow and audiences overlap. Within an alcohol context, young people use audience segregation, mystification and misrepresentation, and justification techniques to manage multiple identities.

Our findings provide a more complex assessment of Goffman's (1959) division of performances into front and back stage, a "two-faced world of front region and back region behaviour" (p.115). We suggest that these divisions are less clear-cut; performances can be simultaneously front stage and back stage depending on which audience takes priority (Johnson, 2013). For instance, hanging out with friends and sharing alcohol-related stories at break times may be a backstage performance if taking the perspective of young peoples' academic identity (i.e. taking a break from performing front stage in the classroom), but also represent an important front stage performance for the peer audience. Similarly, drinking alcohol with teammates after a rugby game can be simultaneously a backstage performance hidden from the rugby coach and team supporters - but also a front stage performance for the peer audience of teammates. That performances can be simultaneously front and back stage poses a challenge to Goffman's front (performances for the audience) and back stage (relaxing back stage with teammates) division and allows us to question whether there is a back stage after all or whether all performance where others are present should be considered front stage performances. Our findings develop Hancock and Garner's (2009, p.107) work, which suggests that Goffman's division of front and back stage leads to a "self in a hall of mirrors" and "a never-ending reflection of different and multiple front- and back-stage selves." Young people are engaged in a "constant practice of code-shifting" (Ward, 2015, p.222), endlessly switching between multiple and sometimes simultaneous front- and back stage identities and performances, as they encounter different audiences and ever-changing contexts. Our findings also demonstrate that in many cases, young people are moving across 
regions, from one simultaneously front/ back stage performance to another (as an 'outside' region becomes front/back stage), rather than navigating from a back stage to a front stage or vice versa, as was the focus of Goffman's work. Furthermore, rather than going as far as to suggest that young people experience an "infinity of images" of themselves (Hancock and Garner, 2009), paradoxically our findings suggest that while managing multiple identities, young people also experience a degree of consistency and stability in the shape of their everyday interactions with a core set of audiences and contexts.

The Goffmanian perspective we adopt suggests that youth drinking behaviour and the techniques applied to manage (drinking) dramaturgical dilemmas result from the interactions that take place between youth and various audiences. As such our findings hold important implications for social marketing campaigns aiming to promote sensible and responsible drinking amongst youth. Techniques of mystification and misrepresentation were used to present idealized impressions to different audiences. This typically meant concealing drinking and drunkenness from parents (Sheehan and Ridge, 2001), teachers and sports coaches, and accentuating aspects of drinking when presenting the self to an audience of peers - often through drinking stories (Griffin et al., 2009). Social marketing and government demarketing campaigns (Wall, 2005) focusing on the risks and dangers associated with drinking alcohol and employing fear, shame and guilt appeals contribute to the stigmatized nature of young people's drinking, and contradict the themes of sociality, fun, and enjoyment presented in alcohol advertising (Szmigin et al., 2011). Rather than encouraging young people to drink responsibly, these campaigns and initiatives could inadvertently contribute further to the conflicting and contradictory messages surrounding alcohol, prompting young people to understand alcohol consumption as something shameful, which should be concealed from adults. Hackley et al. (2015) further argue that proscriptive alcohol policy messages that focus on the risks and harms associated with drinking alcohol may provide 
material that encourages, rather than dissuades, some groups of young consumers from drinking alcohol to excess. Taken together, the dangers and shame associated with alcohol consumption by social marketing campaigns, alongside the peer pressures to drink to excess, could encourage the performance of drinking and drunkenness in what Goffman would consider to be back stage areas (but which take on a front stage function for the purposes of the peer audience). Social marketing campaigns could engage more directly with young peoples' navigation between different identities, contexts and audiences. For instance, campaigns could tap into the secretive nature of youth alcohol consumption and discourage youth from prioritising audience segregation and mystification above their own safety. More specifically, campaigns might encourage young people to always let their parents know where they are going and agree regular 'check in' times. This suggestion implies that social marketing campaigns and educational efforts ought to also target adult audiences, especially in terms of working with parents around the idea of supporting moderate alcohol consumption, and possibly engaging with ideas around limited alcohol experimentation and less secrecy around drinking. Rather than directing proscriptive messages at one audience, often the case in alcohol-related social marketing campaigns, campaigns aimed at both peer and adult audiences (e.g. parents) could focus on developing a theme of trust and responsibility on both sides - between young people and adult audiences. Social marketing campaigns could also demonstrate an understanding of how alcohol relates to the contexts of youth lives beyond the 'night out' and acknowledge the challenges young people face in navigating audiences with different expectations or attitudes towards alcohol. Such an approach could complement recent youth-driven campaigns that seek to resonate with young people and promote sensible drinking practices (e.g. 'it's the drink talking campaign' by Alcohol Concern; http://www.itsthedrinktalking.co.uk). The view that alcohol and drunkenness can be compartmentalised to identities performed front/back stage at the 
weekend in bars, clubs and at house parties without hindering the successful performance of their identities at school, home and on the sports field could be challenged. This would involve encouraging young people to consider the impact of their front/back stage drinking performances on "outside" regions (Goffman, 1959)- e.g. educational, home and sporting contexts. Alternatively, youth-driven campaigns could provide a platform to share the positive decisions young people make around alcohol, allowing them to successfully manage and perform identities in the multiple stages of their lives. Such campaigns, based upon similar lines to the social media campaigns supporting temporary abstention initiatives (e.g. Dry January), could reduce the negative perceptions of youth drinking, and potentially lessen the inclination to conceal drinking behaviour.

While our study may have implications beyond its focus on young people and alcohol consumption, we suggest caution when translating these findings to other age groups or other risky health behaviours. We focused on alcohol consumption because of its pervasiveness amongst British teens, but other risky health behaviours such as smoking, drug use or risky sexual behaviour could generate a different set of insights. It is also important to recognise the potential limitations of our study from a Goffmanian stance. Our study took place mainly within the educational setting, and we acknowledge that this may have made some participants less willing to openly discuss their lives outside of school/college, and possibly reluctant to disclose information which could be potentially discrediting (Goffman, 1959). Data collection took place in common rooms or spare classrooms to minimize these issues but it is very possible that these issues still persisted. Given the age of participants (1618 years) and the topic under investigation, some participants could have been concerned to some extent with managing the impressions of the researcher (Goffman, 1959) - a female in her mid-20s - and projecting a more favourable version of their alcohol consumption (whether this be emphasising or de-emphasising drinking levels). Although we took steps to 
minimize this very issue (use of multiple methods), we also considered this issue as part of our analysis, recognizing that such self-presentation techniques were used not only in front of peers, parents, teachers, sports coaches but also the researcher. We were aware that the use of paired and group interviews could facilitate a degree of over- or under-communication in front of friends/peers and the researcher (Johnson, 2013), but again this allowed us to observe the use of self-presentation techniques, in this case in the peer context as 'talk' of managing impressions and presenting the self successfully. A limitation of the current study was that our chosen research methods did not allow for direct observation of actual drinking behaviour or young people's interactions with audiences beyond the peer context and the researcher. Such observational research methods were not feasible given the age of participants and the ethical implications that such an immersion into young people's lives would entail. Nevertheless, future studies could adopt observational research methods to observe how young people (over the age of 18) perform the self across multiple contexts, paying particular attention to how alcohol features in these performances - either in action or through 'talk' of their drinking. Future studies may usefully adopt a longitudinal approach to capture how the use of audience segregation, mystification and misrepresentation, and justification techniques alter over the life course. 


\section{References}

Ahuvia, A.C. (2005), 'Beyond the extended self: Loved objects and consumers' identity narratives", Journal of Consumer Research, Vol. 32 No. 1, pp.171-184.

Bahl, S. and Milne, G.R. (2010), "Talking to ourselves: a dialogical exploration of consumption experiences", Journal of Consumer Research, Vol. 37 No. 1, pp.76-195.

Bauman, Z. (2001), "Identity in the globalizing world”, Social Anthropology, Vol. 9 No. 2, p.121-129.

Brennan, L., Fry, M.L. and Previte, J. (2015), "Strengthening social marketing research: Harnessing 'insight' through ethnography”, Australasian Marketing Journal (AMJ), Vol. 23 No. 4, pp.286-293.

Canniford, R., and Shankar, A. (2013), "Purifying practices: How consumers assemble romantic experiences of nature", Journal of Consumer Research, Vol. 39 No. 5, pp.10511069.

Carrington, M. J., Neville, B., and Canniford, R. (2015), “Unmanageable multiplicity: consumer transformation towards moral self-coherence," European Journal of Marketing, Vol. 49 No. 7/8, pp.1300-1325.

Charmaz, K. (2006), Constructing Grounded Theory: A Practical Guide Through Qualitative Analysis, SAGE Publications Ltd, London.

Coleman, L. and Cater, S. (2005), “Underage 'binge' drinking: A qualitative study into motivations and outcomes", Drugs: education, prevention and policy, Vol. 12 No. 2, pp.125136.

Cromwell, P. and Thurman, Q. (2003), “The devil made me do it: Use of neutralizations by shoplifters", Deviant Behavior, Vol. 24 No. 6, pp.535-550. 
Demant, J. and Järvinen, M. (2006), “Constructing maturity through alcohol experienceFocus group interviews with teenagers", Addiction Research \& Theory, Vol. 14 No. 6, pp.589-602.

Denzin, N.K. (1978), The research act: A theoretical introduction to sociological methods, McGraw-Hill, New York.

Firat, A.F, Dholakia, N., and Venkatesh, A. (1995), "Marketing in a postmodern world", European Journal of Marketing, Vol. 29 No. 1, pp.40-56.

Fisk, R.P. and Grove, S.J., (1996), “Applications of impression management and the drama metaphor in marketing: an introduction", European Journal of Marketing, Vol. 30 No. 9, pp.6-12.

Gergen, K.J. (1991), The saturated self: dilemmas of identity in modern life, Basic, New York.

Goffman, E. (1959), The presentation of self in everyday life, Double Day, New York.

Goffman, E. (1961), Encounters: Two studies in the sociology of interaction, Bobbs-Merrill, Oxford, England.

Goulding, C., Shankar, A. and Elliott, R. (2002), "Working weeks, rave weekends: identity fragmentation and the emergence of new communities", Consumption, Markets and Culture, Vol. 5 No. 4, pp.261-284.

Gregory-Smith, D. and Manika, D. (2017), “Consumers' identities and compartmentalisation tendencies in alcohol consumption", Journal of Marketing Management, Published online: 12th Apr 2017, http://dx.doi.org/10.1080/0267257X.2017.1310126. 
Griffin, C., Bengry-Howell, A., Hackley, C., Mistral, W. and Szmigin, I. (2009), "Every time I do it I absolutely annihilate myself': Loss of (self-) consciousness and loss of memory in young people's drinking narratives", Sociology, Vol. 43 No. 3, pp.457-476.

Hackley, C., Bengry-Howell, A., Griffin, C., Szmigin, I., Mistral, W. and Hackley, R.A. (2015), "Transgressive drinking practices and the subversion of proscriptive alcohol policy messages”. Journal of Business Research, Vol. 68 No. 10, pp.2125-2131.

Hackley, C., Bengry-Howell, A., Griffin, C., Mistral, W., Szmigin, I. and Tiwsakul, R. (2013), "Young adults and 'binge' drinking: A Bakhtinian analysis”, Journal of Marketing Management, Vol. 29 No. 7-8, pp.933-949.

Haines, R., Poland, B. and Johnson, J. (2009), "Becoming a 'real' smoker: cultural capital in young women's accounts of smoking and other substance use", Sociology of Health \& Illness, Vol. 31 No. 1, pp.66-80.

Hamilton, K. and Hassan, L. (2010), "Self-concept, emotions and consumer coping: smoking across Europe", European Journal of Marketing, Vol. 44 No. 7/8, pp.1101-1120.

Hancock, B.H. and Garner, R. (2009), Changing theories: New directions in sociology. University of Toronto Press.

Harnett, R., Thom, B., Herring, R. and Kelly, M. (2000), “Alcohol in Transition: Towards a Model of Young Men's Drinking Styles”, Journal of Youth Studies, Vol. 3 No. 1, pp.61-77.

Hartley, J. E. Wight, D. and Hunt, K. (2014), "Presuming the influence of the media: teenagers' constructions of gender identity through sexual/romantic relationships and alcohol consumption”, Sociology of Health \& Illness, Vol. 36 No. 5, pp.772-786.

Heath, S. and Walker, C. (2011), Innovations in Youth Research, Palgrave Macmillan, Basingstoke, GB

James, W. (1890), The Principles of Psychology, Henry Holt and Company, New York. 
Johnson, P. (2013), “'You think you're a rebel on a big bottle': teenage drinking, peers and performance authenticity”, Journal of Youth Studies, Vol. 16 No. 6, pp.747-758.

Kjeldgaard, D. and Askegaard, S. (2006). "The glocalization of youth culture: The global youth segment as structures of common difference", Journal of Consumer Research, Vol. 33 No. 2, pp.231-247.

MacLean, S. (2016), “Alcohol and the constitution of friendship for young adults", Sociology, Vol. 50 No. 1, pp.93-108.

Martinic, M. and Measham, F. (2008), Swimming with crocodiles: The culture of extreme drinking, Routledge, New York.

Measham, F. (2008), “The turning tides of intoxication: young people's drinking in Britain in the 2000s", Health Education, Vol. 108 No. 3, pp.207-222.

Nachtigal, A. and Kidron, C.A. (2015), "Existential multiplicity and the late-modern smoker: negotiating multiple identities in a support group for smoking cessation", Sociology of Health \& Illness, Vol. 37 No. 3, pp.452-467.

Nairn, K., Higgins, J., Thompson, B., Anderson, M. and Fu, N. (2006), “'It's just like the teenage stereotype, you go out and drink and stuff': Hearing from young people who don't drink”, Journal of Youth Studies, Vol. 9 No. 3, pp.287-304.

Palmer, C. (2015), Rethinking Drinking and Sport: New Approaches to Sport and Alcohol, Ashgate Publishing, Ltd, Surrey, England.

Pounders, K., Pounders, K., Kowalczyk, C. M., Kowalczyk, C. M., Stowers, K., and Stowers, K. (2016). "Insight into the motivation of selfie postings: impression management and selfesteem”, European Journal of Marketing, Vol. 50 No. 9/10, pp.1879-1892. 
Robinson, L. and Schulz, J. (2016), "Eliciting Frontstage and Backstage Talk with the Iterated Questioning Approach", Sociological Methodology, Vol. 46 No, 1, pp.53-83.

Rúdólfsdóttir, A.G. and Morgan, P. (2009), “'Alcohol is my friend”: Young middle class women discuss their relationship with alcohol", Journal of community \& applied social psychology, Vol. 19 No. 6, pp.492-505.

Saldana, J. (2009), The Coding Manual for Qualitative Researchers, Sage, Thousand Oaks, CA.

Schacht, S.P. (1996), "Misogyny on and off the "pitch": The gendered world of male rugby players", Gender \& Society, Vol. 10 No. 5, pp.550-565.

Scott, S. (2005), "The red, shaking fool: dramaturgical dilemmas in shyness", Symbolic Interaction, Vol. 28 No. 1, pp.91-110.

Sheehan, M. and Ridge, D. (2001), "You become really close...you talk about the silly things you did, and we laugh": The role of binge drinking in female secondary students' lives", Substance use \& misuse, Vol. 36 No. 3, pp.347-372.

Spiggle, S. (1994), “Analysis and Interpretation of Qualitative Data in Consumer Research", Journal of Consumer Research, Vol. 21 December, pp.491-503.

Sykes, G.M. and Matza, D. (1957), “Techniques of neutralisation: A theory of delinquency”, American Sociological Review, Vol. 22 No. 6, pp.664-670.

Szmigin, I., Griffin, C., Mistral, W., Bengry-Howell, A., Weale, L. and Hackley, C. (2008), "Re-framing 'binge drinking' as calculated hedonism: Empirical evidence from the UK", International journal of drug policy, Vol. 19 No. 5, pp.359-366. 
Szmigin, I., Bengry-Howell, A., Griffin, C., Hackley, C. and Mistral, W. (2011), "Social marketing, individual responsibility and the "culture of intoxication", European Journal of Marketing, Vol. 45 No. 5, pp.759-779.

Thompson, L., Pearce, J., and Barnett, R. (2009), "Nomadic identities and socio-spatial competence: making sense of post-smoking selves”, Social \& Cultural Geography, Vol. 10 No. 5, pp.565-581.

Thurnell-Read, T. (2015), Drinking Dilemmas: Space, Culture and Identity, Routledge, New York, NY.

Tian, K., and Belk, R. W. (2005), "Extended self and possessions in the workplace”, Journal of Consumer Research, Vol. 32 No. 2, pp.297-310.

Turner, V. (1969), The Ritual Process: Structure and antistructure, Aldine de Gruyter, New York.

Wall, A.P. (2005), “Government demarketing: different approaches and mixed messages", European Journal of Marketing, Vol. 39 No. 5/6, pp.421-427.

Ward, M.R.M. (2015), “The Chameleonisation of Masculinity: Jimmy’s Multiple Performances of a Working-Class Self”, Masculinities \& Social Change, Vol. 4 No. 3, pp. 215-240.

Willis, P.E. (1977), Learning to labour: How working class kids get working class jobs, Saxon House, Westmead, England. 